\title{
NO gas sensing at room temperature using single titanium oxide nanodot sensors created by atomic force microscopy nanolithography
}

\author{
Li-Yang Hong and Heh-Nan Lin*
}

\author{
Full Research Paper \\ Address: \\ Department of Materials Science and Engineering, National Tsing \\ Hua University, Hsinchu 30013, Taiwan \\ Email: \\ Heh-Nan Lin* - hnlin@mx.nthu.edu.tw \\ * Corresponding author \\ Keywords: \\ atomic force microscopy nanolithography; photo-activation; \\ photo-recovery; resistive NO gas sensor; titanium oxide nanodot \\ sensor
}

\author{
Beilstein J. Nanotechnol. 2016, 7, 1044-1051. \\ doi:10.3762/bjnano.7.97 \\ Received: 08 March 2016 \\ Accepted: 05 July 2016 \\ Published: 20 July 2016 \\ This article is part of the Thematic Series "Nanostructures for sensors, \\ electronics, energy and environment III". \\ Guest Editor: N. Motta \\ (C) 2016 Hong and Lin; licensee Beilstein-Institut. \\ License and terms: see end of document.
}

\begin{abstract}
In this work, the fabrication of single titanium oxide nanodot (ND) resistive sensors for NO gas sensing at room temperature is reported. Two atomic force microscopy nanolithography methods, nanomachining and nano-oxidation, are employed. A single titanium nanowire (NW) is created first along with contact electrodes and a single titanium oxide ND is subsequently produced in the NW. Gas sensing is realized by the photo-activation and the photo-recovery approaches. It is found that a sensor with a smaller ND has better performance than a larger one. A response of 31\%, a response time of $91 \mathrm{~s}$, and a recovery time of $184 \mathrm{~s}$ have been achieved at a concentration of $10 \mathrm{ppm}$ for a ND with a size of around $80 \mathrm{~nm}$. The present work demonstrates the potential application of single metal oxide NDs for gas sensing with a performance that is comparable with that of metal oxide nanowire gas sensors.
\end{abstract}

\section{Introduction}

In recent years, gas sensors have been widely used in a variety of fields, such as medical diagnosis [1,2], environmental monitoring [3] and combustion emission control [4]. Among all types of gas sensors, resistor-type gas sensors based on semiconducting metal oxide nanomaterials [5-8] are more attractive than conventional devices [9]. The advantages include high sensitivity, high stability, fast detection and recovery, low power consumption, relatively low cost, and small size $[9,10]$. These advantages enable semiconducting metal oxide sensors to be implemented on integrated circuits for portable applications $[5,11]$.

Semiconducting metal oxide gas sensors generally need to work at high temperatures due to the high energy required for surface reactions $[5,12,13]$. However, a high operating temperature results in issues with durability and reliability of the device [5]. To overcome this drawback, light-assisted approaches including photo-activation [12-21] and photo-recovery [22,23] have 
been shown effective to enable gas sensing at room temperature.

The sensing material in a semiconducting metal oxide sensor is commonly synthesized by a bottom-up approach, such as chemical vapour deposition [11,15,16,23], thermal deposition [12], solution growth [19], and electrospinning [24]. Alternatively, a lithographic approach is also suitable for producing the sensing metal oxide material. Previously, atomic force microscopy (AFM) nano-oxidation has been utilized for the fabrication of titanium oxide nanowire (NW) gas sensors $[25,26]$.

NO gas sensing at low concentrations is beneficial for human health [1,2] and environmental monitoring [3]. Various types of metal oxide nanomaterials have been utilized for $\mathrm{NO}$ or $\mathrm{NO}_{2}$ gas sensing, e.g., $\mathrm{SnO}_{2}$ [12,15-17], $\mathrm{ZnO}$ [13,14,17-20,23], $\mathrm{In}_{2} \mathrm{O}_{3}$ [22], and $\mathrm{TiO}_{2}$ [24,27-29]. AFM nanolithography is a valuable technique for the fabrication of nanostructures and sensors [30,31]. Recently, we have reported on the fabrication of single titanium oxide nanodot (ND) ultraviolet (UV) sensors by AFM nanomachining and nano-oxidation [32]. In the present work, the application of single titanium oxide ND sensors for NO gas sensing at room temperature is reported. The performance of the ND gas sensors compares reasonably with metal oxide NW gas sensors reported in the literature.

\section{Experimental}

A schematic diagram of the AFM nanolithography [30,32] procedure is shown in Figure 1. A $40 \mathrm{~nm}$ thick poly(methylmethacrylate) (PMMA) film was spin-coated on a Si substrate that had a thick oxide layer. By using an AFM (Smena, NT-MDT, Russia), a straight nanogroove was generated in the PMMA film. A Ti film was deposited by electron-beam deposition and a single Ti NW was created after lift-off. Au contact electrodes were subsequently created on the sides of the NW by standard photolithography. The details can be found in our previous reports $[33,34]$. For nano-oxidation, the tip was moved to the middle of the $\mathrm{NW}$ and a voltage pulse $(-10 \mathrm{~V}$ and $500 \mathrm{~ms}$ ) was applied to the tip. A single titanium oxide ND sensor was thus obtained [32]. The morphologies of the NW and the ND were examined by another AFM (Dimension Icon, Bruker, U.S.A.).

The fabricated ND sensor was put in a vacuum chamber and connected to a Keithley 2400 source measure unit. Prior to a sensing cycle, the chamber was pumped to low vacuum (ca. $10^{-3}$ Torr) and the valve was closed. A mixture of NO (500 ppm) and $\mathrm{N}_{2}$ gas was injected into the chamber and a sensing cycle was started. With a mass flow controller, a specific NO concentration was quickly established in the chamber for sensing. After a sufficient sensing time (which is shown in blue

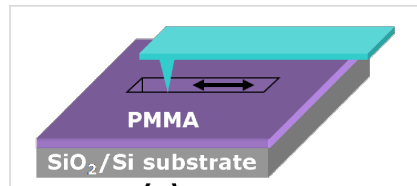

(a)

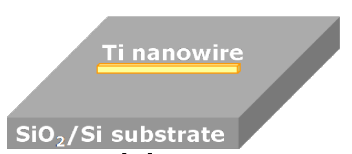

(c)

(e)

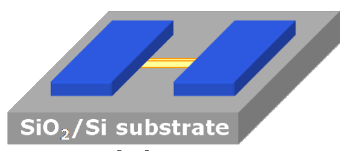

(g)

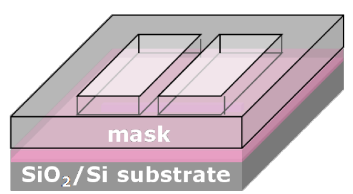

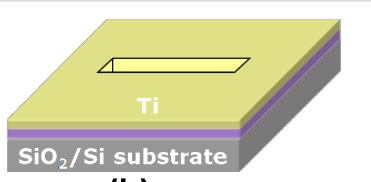

(b)

(d)

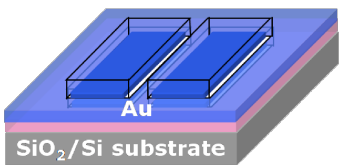

(f)

(h)
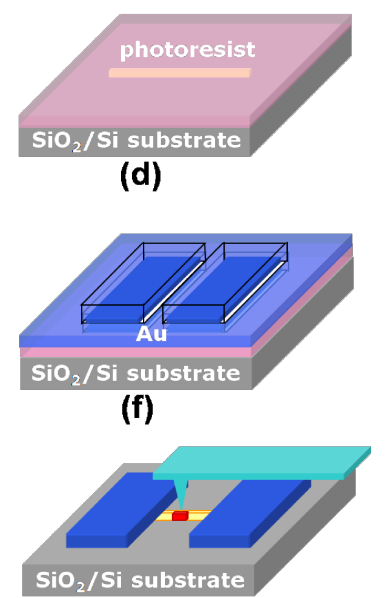

Figure 1: A schematic diagram showing the fabrication of a single titanium oxide ND gas sensor. (a) PMMA spin-coated and AFM nanomachining, (b) Ti deposition, (c) PMMA lift-off, (d) photoresist spin-coated, (e) exposure and development, (f) Au deposition, (g) photoresist lift-off, and (h) AFM nano-oxidation. (Adapted from [32]).

in the current-response figures), the chamber was evacuated again for NO desorption (which is shown in white in the current-response figures). After the pumping, the sensing cycle ended and the next cycle was started. The time-dependent current of the sensor at a bias voltage of 10 or $5 \mathrm{~V}$ was recorded. A UV light-emitting diode $\left(310 \mathrm{~nm}\right.$ at $\left.0.3 \mathrm{~mW} \cdot \mathrm{cm}^{-2}\right)$ was placed above the sensor for UV-assisted sensing. Two sensing modes were applied. For the first, called UV-activation mode, the sensor was under constant UV illumination through the whole measurement. For the second, called UV-recovery mode, the UV light was turned on after sensing for NO desorption. (Note that the chamber was under pumping.) The UV light was then turned off after a certain time. (Note that the chamber was still under pumping after the light was turned off.)

\section{Results and Discussion}

Two ND gas sensors with different sizes have been fabricated. The smaller one will be called sensor A and the larger one sensor B. An AFM topographic image of sensor A is shown in Figure 2a and a cross-sectional plot is shown Figure 2c. The ND has a length, a width and a height of around 50, 80 and $26 \mathrm{~nm}$, respectively. A topographic image of sensor B is shown in Figure $2 \mathrm{~b}$ and a cross-sectional plot is shown in Figure $2 \mathrm{~d}$. The ND is larger with a length, a width and a height of around 134, 120 and $16 \mathrm{~nm}$, respectively. The surface to volume ratio is an important factor for the sensing performance. Taking the NDs 
as simple rectangular cuboids, the estimated volume and surface area (only five surfaces) for sensor A are around $104 \times 10^{3} \mathrm{~nm}^{3}$ and $10.8 \times 10^{3} \mathrm{~nm}^{2}$, respectively. The surface to volume ratio is roughly $0.103 \mathrm{~nm}^{-1}$. The estimated volume and surface area for sensor $\mathrm{B}$ are around $257 \times 10^{3} \mathrm{~nm}^{3}$ and $24.2 \times 10^{3} \mathrm{~nm}^{2}$, respectively. The surface to volume ratio is roughly $0.094 \mathrm{~nm}^{-1}$. Therefore, sensor A has a larger surface to volume ratio.
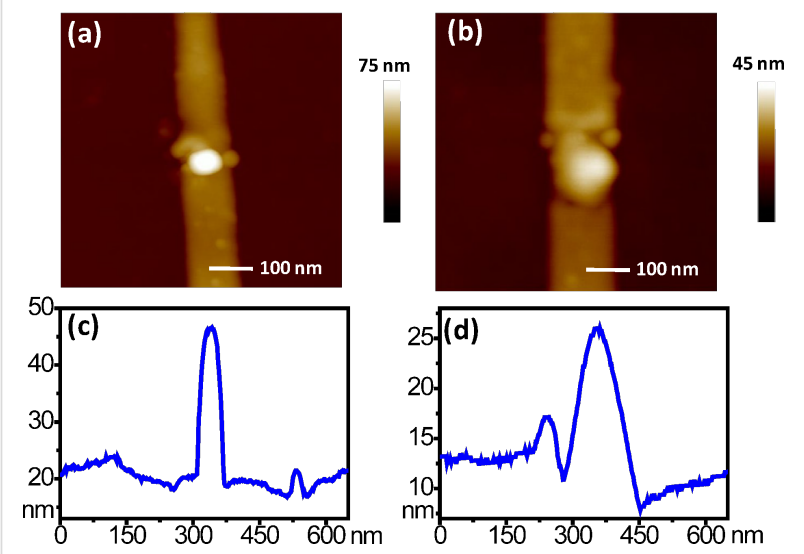

Figure 2: $(a, b)$ AFM topographic images of the two NDs of sensors $A$ and $B$, respectively. (c,d) Cross-sectional plots of the two NDs.

The generation of the NDs after nano-oxidation shown in Figure 2 is clear evidence of the formation of titanium oxide. Also, Auger electron spectroscopy analysis confirmed that the Ti was oxidized [32]. The compositions of the NDs, however, cannot be exactly determined and are simply $\mathrm{TiO}_{x}$. Also, sensor A has a larger resistance due to the smaller ND size. (The current-voltage relationships of the two ND sensors before NO sensing are shown in Figure S1 in Supporting Information File 1.) We discussed the electrical properties of the sensors in our previous report [32]. A $\mathrm{TiO}_{x} \mathrm{ND}$ behaves like an n-type semiconductor due to oxygen vacancies. When NO molecules (or $\mathrm{O}_{2}$ molecules under ambient environment) adsorb on the ND surface, they become negatively charged by catching electrons. The conductance of the ND with $\mathrm{NO}\left(\right.$ or $\left.\mathrm{O}_{2}\right)$ adsorption is thus smaller than that in the pristine state of the ND (i.e., without adsorbed molecules). Under UV illumination, the ND conductance becomes larger since the adsorbed $\mathrm{NO}\left(\right.$ or $\mathrm{O}_{2}$ ) molecules are neutralized by photo-generated holes and leave the ND surface [35]. Detailed mechanisms will be discussed later.

Figure 3a shows the current response of sensor A at $15 \mathrm{ppm}$ NO and a bias of $10 \mathrm{~V}$ in the UV-activation mode. (Note that it was confirmed first that pure $\mathrm{N}_{2}$ gas had no effect on the sensor current.) The starting current (ca. $0.9 \mu \mathrm{A}$ ) is larger than the current under ambient environment since the sensor is under UV irradiation. The current decreases after NO injection (blue region) and stabilizes after a certain time. (The NO exposure times in the blue regions in Figure 3a are around 215, 305 and 230 s, respectively.) It gradually increases when the NO gas is pumped out (white region). As can be seen, the current variations are consistent for the three cycles. Figure $3 \mathrm{~b}$ shows the current response at 10,15 and $20 \mathrm{ppm}$. (The exposure times in Figure $3 \mathrm{~b}$ are 155,230 and $315 \mathrm{~s}$, respectively.) It is clear that the current decrease becomes larger as the concentration rises, because more molecules adsorb on the surface. Furthermore, it takes longer time for the current to return to its original value as the concentration gets higher. Figure $3 \mathrm{c}$ shows the current response at 10, 15, and $20 \mathrm{ppm} \mathrm{NO}$ and at $5 \mathrm{~V}$. (The exposure times in Figure 3c are 170, 315, 230 and 370 s.) In comparison with Figure $3 b$, it takes longer time for the current to return to
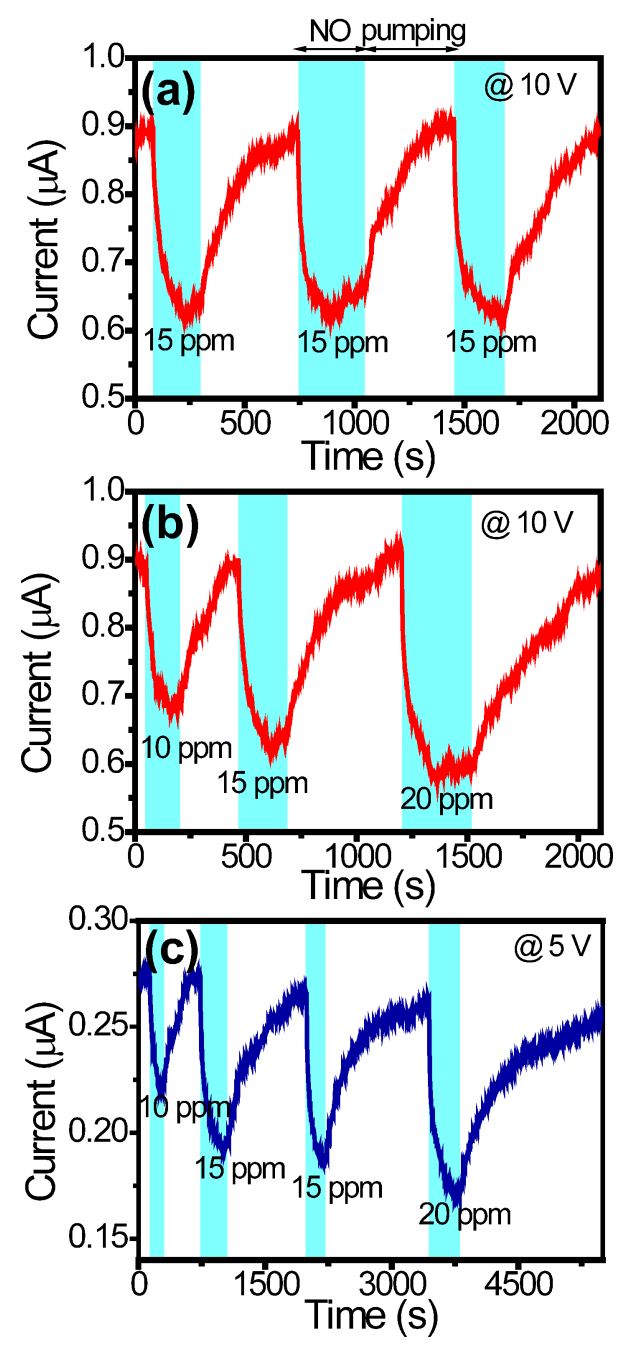

Figure 3: (a) The current response of sensor $A$ at $10 \mathrm{~V}$ and $15 \mathrm{ppm}$ $\mathrm{NO}$, and $(\mathrm{b}, \mathrm{c})$ the current responses at 10 and $5 \mathrm{~V}$, respectively, for various concentrations in the UV-activation mode. The blue regions indicate NO presence and the white regions indicate pumping. 
its original value. The faster recovery (i.e., faster NO desorption) in Figure 3b is caused by the self-heating effect [36,37]. When operating at a larger bias, the sensor temperature is higher owing to more Joule heat. The rate of desorption increases accordingly. A larger operating voltage is thus beneficial for sensing, but at the cost of higher risk of breaking down.

Figure 4 shows the performance of sensor $\mathrm{A}$ at $10 \mathrm{~V}$ calculated from Figure 3b. The response $S$ is defined as $S=\Delta R / R_{0}$, where $\Delta R$ is the resistance increase after $\mathrm{NO}$ adsorption and $R_{0}$ the initial resistance in a blue region in Figure $3 \mathrm{~b}$. The responses are 31,41 , and $52 \%$ for 10,15 , and $20 \mathrm{ppm}$, respectively, and plotted in Figure 4a. (The resistances before and after NO adsorption are shown in Table S1 in Supporting Information File 1.) The response time $t_{\text {res }}$ is defined as the time required for the current to decrease to $10 \%$ of the initial current during NO exposure. The results are 91,86 , and $81 \mathrm{~s}$ for 10,15 , and $20 \mathrm{ppm}$, respectively, and plotted in Figure $4 \mathrm{~b}$. The recovery time $t_{\text {rec }}$ is defined as the time required for the current to increase to $90 \%$ of the original current when NO is being pumped out. The results are 184, 363, and $477 \mathrm{~s}$ for 10,15 , and 20 ppm, respectively, and also plotted in Figure 4b. Response and recovery time both increase as the concentration rises. Since there are more adsorbed molecules on the ND surface at a higher concentration, it is reasonable that the response becomes larger. Also, it takes a longer time for the molecules to leave the surface during recovery. On the other hand, the response time has an opposite trend. This can be attributed to faster molecular adsorption on the ND surface at a higher concentration.
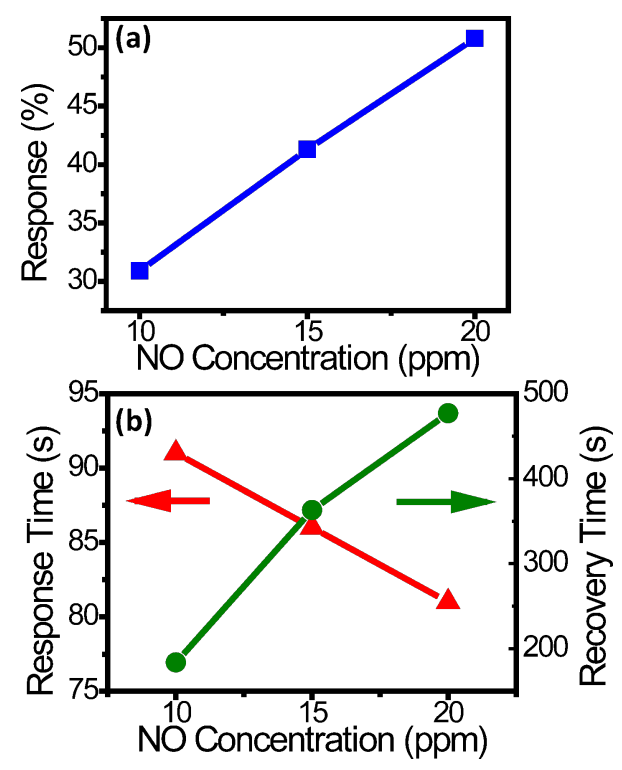

Figure 4: (a) Response and (b) response time and recovery time as a function of the concentration for sensor $A$ at $10 \mathrm{~V}$ in the UV-activation mode calculated from Figure $3 \mathrm{~b}$.
Figure 5a shows the current response of sensor $\mathrm{A}$ at $10 \mathrm{~V}$ in the UV-recovery mode. At the beginning, the UV irradiation is turned on for $\mathrm{O}_{2}$ desorption (the chamber is also under pumping) and the current rises immediately. When the current reaches a high value (roughly $1.1 \mu \mathrm{A}$ in Figure 5a), the UV irradiation is then turned off. The current gradually decreases due to re-adsorption of $\mathrm{O}_{2}$. (Note that re-adsorption occurs due to the low vacuum in spite that the chamber is still under pumping.) When it reaches an approximately steady value of $0.8 \mu \mathrm{A}, \mathrm{NO}$ is injected and the sensing starts. (A finer time scale current response is shown in Figure S2 in Supporting Information File 1 and it reveals the current is approximately steady at $0.8 \mu \mathrm{A}$.) After a sufficient sensing time, the UV irradiation is turned on (yellow region) for NO desorption and the process repeats. From the current response, the responses are
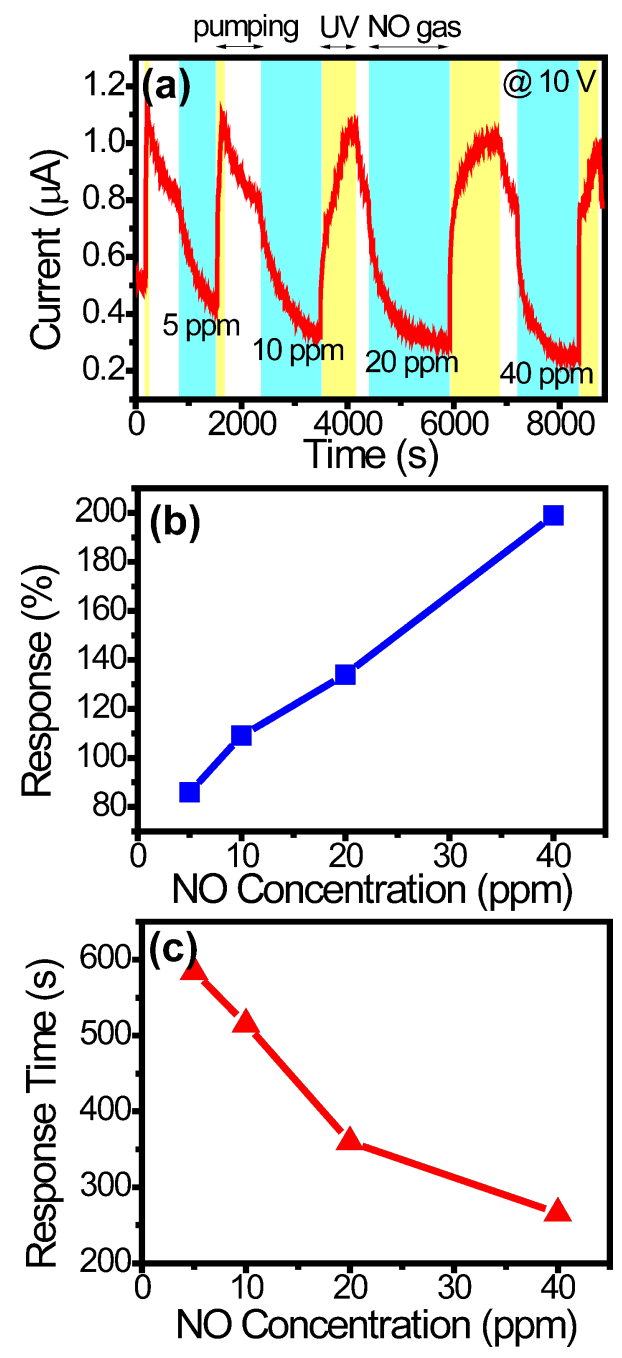

Figure 5: (a) The current response of sensor $A$ at $10 \mathrm{~V}$ in the UV-recovery mode. (b) Response and (c) response time as a function of the concentration. 
$86,108,134$, and $199 \%$ for $5,10,20$, and $40 \mathrm{ppm}$, respectively, and plotted in Figure 5b. The response times are 584, 515, 360, and $266 \mathrm{~s}$, respectively, and plotted in Figure 5c. It is difficult to determine the recovery times in the UV-recovery mode and, therefore, they are not shown.

The responses in Figure $5 \mathrm{~b}$ are roughly three times as high as those in Figure 4a, suggesting that the UV-recovery mode is more sensitive. In the UV-activation mode, desorption occurs to some extent during NO exposure because of the UV irradiation. On the contrary, in the UV-recovery mode, there is no desorption during NO exposure. Consequently, there are more adsorbed molecules and the response is larger. The response times in Figure 5c are much longer than those in Figure 4b, suggesting that the UV-recovery mode has a slower response. This can be explained again by molecular adsorption and desorption. In the UV-activation mode, the adsorption and desorption of NO molecules rapidly reach a dynamic equilibrium under UV illumination during NO exposure. In the UV-recovery mode, it takes much longer time to reach full adsorption during NO exposure. Therefore, the response is much slower.

Figure 6a shows the current response of sensor B at $10 \mathrm{~V}$ between 50 and $500 \mathrm{ppm}$ in the UV-activation mode. (The current response at $5 \mathrm{~V}$ in the UV-activation mode is shown in Figure S3 in Supporting Information File 1 for comparison.) The responses are $9,16,27$, and $47 \%$ for $50,100,250$, and $500 \mathrm{ppm}$, respectively, and plotted in Figure $6 \mathrm{~b}$. (The resistances before and after NO adsorption are also shown in Table S1 in Supporting Information File 1.) As expected, the response increases as the NO concentration rises. The response times are 138, 94, 40, and $16 \mathrm{~s}$, and the recovery times are 100,160, 180, and $210 \mathrm{~s}$ for the four concentrations, respectively. They are all plotted in Figure 6c. Similarly to the results in Figure 4, the response time decreases and the recovery time increases as the concentration rises.

A summary of the responses, the response times, and the recovery times of the two sensors obtained at $10 \mathrm{~V}$ in the UV-activation mode is shown in Table 1. As has been discussed previously, the response and the recovery time both increase as the concentration rises, whereas the response time has an opposite trend. Furthermore, sensor A has larger and faster response, but longer recovery than sensor B. The first two benefits can be explained by two factors. One is that the ND in sensor A has a larger surface to volume ratio. The other is due to the fact that the depletion layer thickness after adsorption is roughly equal to the Debye length $[5,17,38]$. Therefore, the conduction channel in the ND of sensor A after adsorption is narrower than that in sensor $\mathrm{B}$. The combination of the two

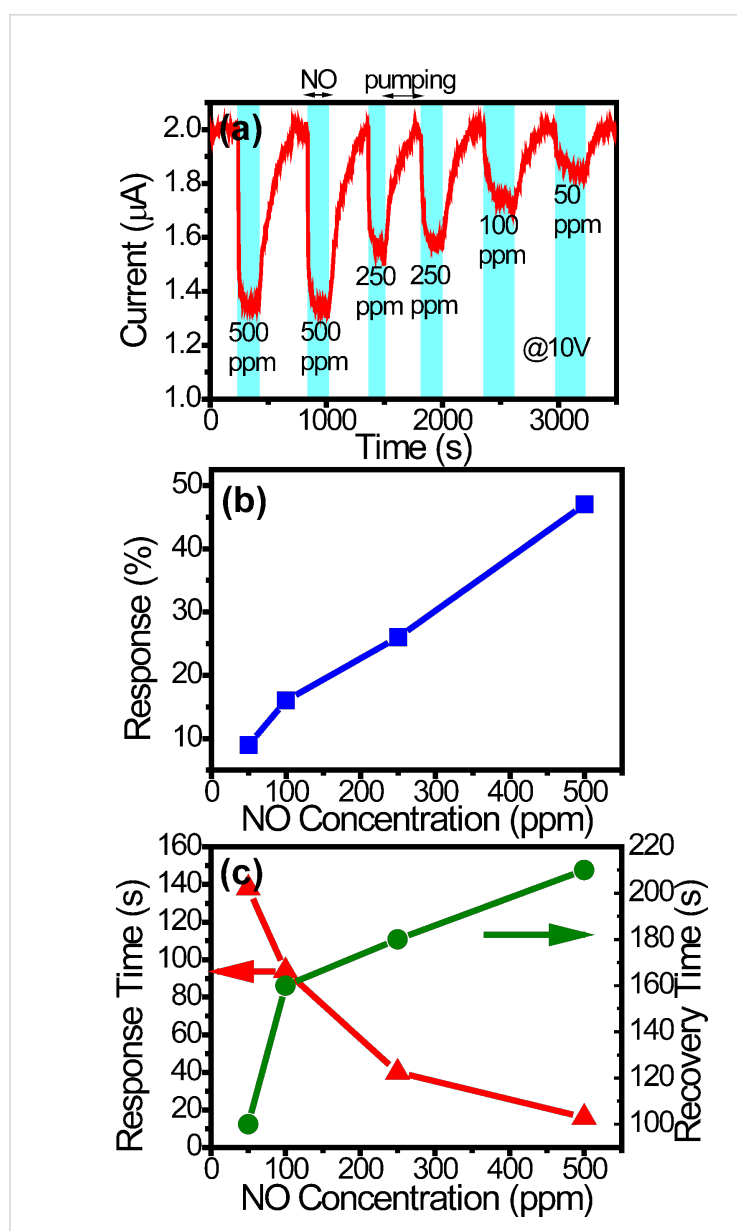

Figure 6: (a) The current responses of sensor B at $10 \mathrm{~V}$ in the UV-activation mode. (b) The response and (c) the response time and the recovery time versus the concentration.

factors makes the smaller sensor A more sensitive. The longer recovery of sensor A may be explained by the following argument: There are more photo-generated charge carriers in sensor $\mathrm{B}$ than in sensor A under UV illumination since sensor B is larger. The adsorbed NO molecules can thus be more efficiently neutralized and leave the ND surface. As a result, sensor B has shorter recovery.

Additionally, it is worth mentioning that the background $\mathrm{N}_{2}$ pressure was 2000 times that of the NO pressure and roughly a few percents of one atmosphere in the above measurements. In order to verify if a higher $\mathrm{N}_{2}$ pressure affected the sensing results, a measurement was conducted with the $\mathrm{N}_{2}$ pressure raised to one atmosphere after NO sensing. It was found that there was no change in the current response. (The current response is shown in Figure S4 in Supporting Information File 1.) It is therefore reasonable to expect that the present sensing results will not change in a high-pressure $\mathrm{N}_{2}$ environment. 
Table 1: A summary of the responses, the response times, and the recovery times for the two sensors obtained at $10 \mathrm{~V}$ in the UV-activation mode. $C$ is the NO concentration.

\begin{tabular}{lllll} 
sensor & $C(\mathrm{ppm})$ & $S(\%)$ & $t_{\text {res }}(\mathrm{s})$ & $t_{\text {rec }}(\mathrm{s})$ \\
\hline A & 10 & 31 & 91 & 184 \\
& 15 & 41 & 86 & 363 \\
B & 20 & 52 & 81 & 477 \\
& 50 & 9 & 138 & 100 \\
& 100 & 16 & 94 & 160 \\
& 250 & 27 & 40 & 180 \\
& 500 & 47 & 16 & 210
\end{tabular}

Possible mechanisms for $\mathrm{NO}$ or $\mathrm{NO}_{2}$ sensing by using semiconducting metal oxide nanomaterials have been proposed and discussed in previous works [19,20,26,38]. Based on these works, Figure 7 shows the gas sensing mechanisms for the single titanium oxide ND sensor in the UV-recovery and the UV-activation modes. In the UV-recovery mode, $\mathrm{O}_{2}$ and $\mathrm{NO}$ molecules react with electrons to form chemisorbed oxygen ions $\left(\mathrm{O}_{2}^{-}\right.$(ads) and nitric oxide ions $\left(\mathrm{NO}^{-}{ }_{(\mathrm{ads})}\right)$ prior to UV irradiation, which are shown in Figure 7a and Figure $7 \mathrm{~b}$. The chemical reactions for NO are described by $[20,38]$ :

$$
\begin{gathered}
\mathrm{NO}_{(\mathrm{g})}+e^{-} \rightarrow \mathrm{NO}_{(\text {ads })}^{-}, \\
2 \mathrm{NO}_{(\mathrm{g})}+e^{-} \rightarrow \mathrm{N}_{2(\mathrm{~g})}+\mathrm{O}_{2(\mathrm{ads})}^{-} .
\end{gathered}
$$

Without UV illumination, the chemisorbed ions are too stable to be removed by pumping. Under UV illumination, the ions are first neutralized by photogenerated holes and then react again with photogenerated electrons [13], which is shown in Figure 7c. The chemical reactions for NO can be similarly described by:

$$
\mathrm{NO}_{(\mathrm{g})}+e_{(\mathrm{h} v)}^{-} \rightarrow \mathrm{NO}_{(\mathrm{h} v)}^{-}
$$

$$
2 \mathrm{NO}_{(\mathrm{g})}+e_{(\mathrm{h} v)}^{-} \rightarrow \mathrm{N}_{2(\mathrm{~g})}+\mathrm{O}_{2(\mathrm{~h} v)}^{-}
$$

Unlike the chemisorbed ions, the photoinduced ions $\left(\mathrm{O}_{2}{ }^{-}\right.$(hv) and $\mathrm{NO}_{(\mathrm{h} v)}^{-}$) are only weakly bound to the ND surface. They can be easily removed by pumping as shown in Figure $7 \mathrm{~d}$. In the UV-activation mode, the ND is under continuous UV irradiation. There are no chemisorbed ions before NO sensing, which is shown in Figure 7e. Photoinduced ions are then created after NO injection as shown in Figure 7f. The photoinduced ions are finally removed by pumping as shown in Figure $7 \mathrm{~g}$.

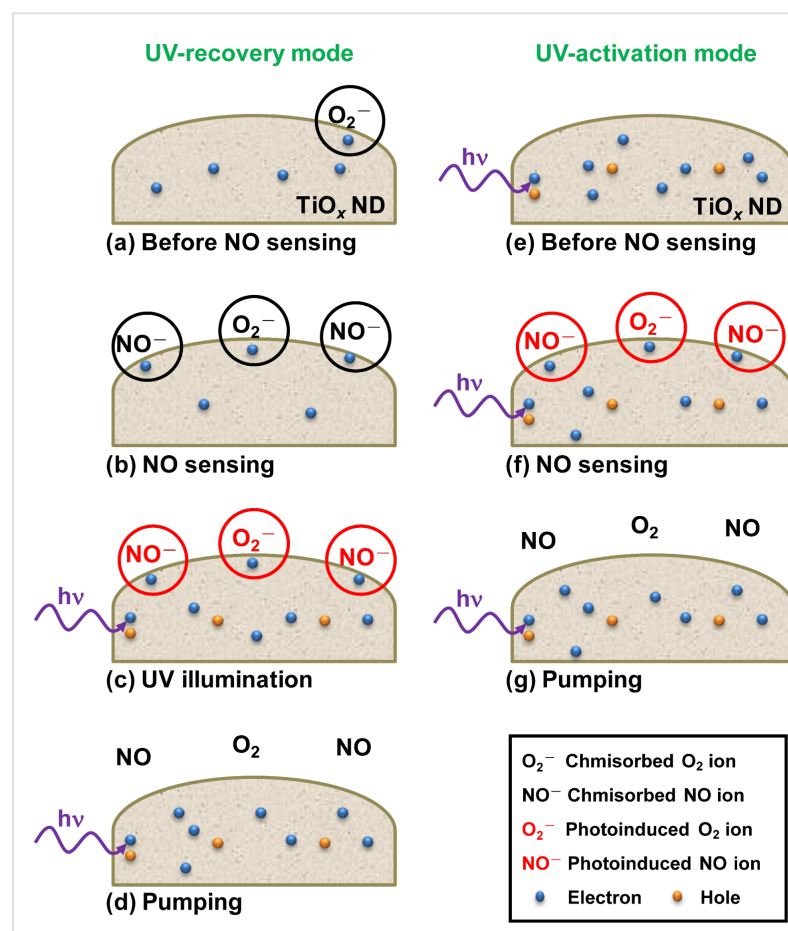

Figure 7: Diagram illustrating NO gas sensing mechanisms for the single titanium oxide ND sensor in the UV-recovery and the UV-activa-

\begin{tabular}{|c|c|c|c|c|c|c|c|}
\hline material & gas & $C(\mathrm{ppm})$ & $S(\%)$ & $t_{\text {res }}(\mathrm{s})$ & $t_{\mathrm{rec}}(\mathrm{s})$ & light intensity $\left(\mathrm{mW} \cdot \mathrm{cm}^{-2}\right)$ & ref. \\
\hline $\mathrm{CdS} / \mathrm{ZnO} \mathrm{NWs}$ & $\mathrm{NO}_{2}$ & 1 & 337 & 40 & 230 & 0.68 (@ 468 nm) & [21] \\
\hline Au-ZnO nanocomposites & NO & 2 & 388 & ca. 1000 & - & - (@ 550 nm) & [20] \\
\hline $\begin{array}{l}\text { ZnO NWs } \\
\mathrm{SnO} 2 \mathrm{NWs} \\
\mathrm{SnO} 2 / \mathrm{ZnO} \mathrm{NWs}\end{array}$ & $\mathrm{NO}_{2}$ & 5 & $\begin{array}{l}4 \\
80 \\
519\end{array}$ & $\begin{array}{l}110 \\
90 \\
100\end{array}$ & $\begin{array}{l}230 \\
220 \\
220\end{array}$ & $1.2(@ 365$ nm) & [17] \\
\hline $\begin{array}{l}\mathrm{ZnO} \text { nanosheets } \\
\mathrm{Au} / \mathrm{ZnO} \text { nanosheets }\end{array}$ & $\mathrm{NO}_{2}$ & 5 & $\begin{array}{l}37 \\
355\end{array}$ & $\begin{array}{l}8 \\
6\end{array}$ & $\begin{array}{l}290 \\
320\end{array}$ & $1.2(@ 365$ nm) & [18] \\
\hline ZnO nanoline & $\mathrm{NO}_{2}$ & 20 & 108 & ca. 600 & ca. 300 & 25 (@365 nm) & [14] \\
\hline $\mathrm{TiO}_{x} \mathrm{ND}$ & NO & 10 & 31 & 91 & 184 & $0.3(@ 310$ nm) & this work \\
\hline
\end{tabular}
tion modes.

Table 2 shows a comparison of sensing performances of $\mathrm{NO}$ or $\mathrm{NO}_{2}$ metal oxide sensors operated in the photo-activation mode 
at room temperature reported in the literature. Although not better, the performance of sensor A compares reasonably with these reported results. Furthermore, it can be seen that the performances of metal oxides with $\mathrm{Au}$ are much better those of pure metal oxides, which is due to the plasmonic effect $[18,20]$. It is expected that the present ND sensors can be improved in a similar fashion, e.g., by creating Au nanoparticles on the ND surface.

\section{Conclusion}

In summary, single titanium oxide ND sensors are realized by AFM nanolithography and used for NO gas sensing. A Ti NW is generated first by AFM nanomachining and a titanium oxide ND is then produced in the NW by AFM nano-oxidation. With contact electrodes, a resistive ND gas sensor is created. For gas sensing at room temperature, light-assisted approaches, namely the UV-activation and the UV-recovery modes, are utilized. Two ND sensors have been fabricated. For the smaller sensor with a ND size of $80 \mathrm{~nm}$, a response of $31 \%$, a response time of $91 \mathrm{~s}$, and a recovery time of $184 \mathrm{~s}$ have been achieved at $10 \mathrm{ppm}$ NO in the UV-activation mode. For the larger sensor with a ND size of $120 \mathrm{~nm}$, a response of $9 \%$, a response time of $138 \mathrm{~s}$, and a recovery time of $100 \mathrm{~s}$ have been achieved at $50 \mathrm{ppm}$ NO in the UV-activation mode. The better performance of the smaller sensor can be attributed to the larger surface to volume ratio and smaller dimensions than the Debye length. The present work reveals the usefulness of single metal oxide NDs for gas sensing with reasonable performance that can be compared with metal oxide NW gas sensors.

\section{Supporting Information}

Supporting Information features the current-voltage curves of sensors A and B before NO sensing, the resistances of sensors A and B before and after NO adsorption obtained from the current responses at a bias of $10 \mathrm{~V}$ as shown in the Figures, a finer time scale current response of sensor $\mathrm{A}$ at $10 \mathrm{~V}$ in the UV-recovery mode, the current response of sensor $\mathrm{B}$ at $5 \mathrm{~V}$ in the UV-activation mode, and the current response of sensor $\mathrm{B}$ at $10 \mathrm{~V}$ due to the injection of $500 \mathrm{ppm} \mathrm{NO}$ and subsequent high-pressure $\mathrm{N}_{2}$.

\section{Supporting Information File 1}

Additional experimental data.

[http://www.beilstein-journals.org/bjnano/content/ supplementary/2190-4286-7-97-S1.pdf]

\section{Acknowledgements}

This work was supported by the Ministry of Science and Technology, Taiwan, under Grant No. 104-2221-E-007-074.

\section{References}

1. Righettoni, M.; Amann, A.; Pratsinis, S. E. Mater. Today 2015, 18, 163-171. doi:10.1016/j.mattod.2014.08.017

2. Di Natale, C.; Paolesse, R.; Martinelli, E.; Capuano, R. Anal. Chim. Acta 2014, 824, 1-17. doi:10.1016/j.aca.2014.03.014

3. Wetchakun, K.; Samerjai, T.; Tamaekong, N.; Liewhiran, C.; Siriwong, C.; Kruefu, V.; Wisitsoraat, A.; Tuantranont, A.; Phanichphant, S. Sens. Actuators, B 2011, 160, 580-591. doi:10.1016/j.snb.2011.08.032

4. Docquier, N.; Candel, S. Prog. Energy Combust. Sci. 2002, 28, 107-150. doi:10.1016/S0360-1285(01)00009-0

5. Comini, E.; Sberveglieri, G. Mater. Today 2010, 13, 36-44. doi:10.1016/S1369-7021(10)70126-7

6. Chen, X.; Wong, C. K. Y.; Yuan, C. A.; Zhang, G. Sens. Actuators, B 2013, 177, 178-195. doi:10.1016/j.snb.2012.10.134

7. Ramgir, N.; Datta, N.; Kaur, M.; Kailasaganapathi, S.; Debnath, A. K.; Aswal, D. K.; Gupta, S. K. Colloids Surf., A 2013, 439, 101-116. doi:10.1016/j.colsurfa.2013.02.029

8. Shen, G.; Chen, P.-C.; Ryu, K.; Zhou, C. J. Mater. Chem. 2009, 19, 828-839. doi:10.1039/B816543B

9. Liu, X.; Cheng, S.; Liu, H.; Hu, S.; Zhang, D.; Ning, H. Sensors 2012, 12, 9635-9665. doi:10.3390/s120709635

10. Franke, M. E.; Koplin, T. J.; Simon, U. Small 2006, 2, 36-50. doi:10.1002/smll.200500261

11. Hernandez-Ramirez, F.; Prades, J. D.; Tarancon, A.; Barth, S.; Casals, O.; Jiménez-Diaz, R.; Pellicer, E.; Rodriguez, J.; Juli, M. A.; Romano-Rodriguez, A.; Morante, J. R.; Mathur, S.; Helwig, A.; Spannhake, J.; Mueller, G. Nanotechnology 2007, 18, 495501. doi:10.1088/0957-4484/18/49/495501

12. Law, M.; Kind, H.; Messer, B.; Kim, F.; Yang, P. Angew. Chem., Int. Ed. 2002, 41, 2405-2408. doi:10.1002/1521-3773(20020703)41:13<2405::AID-ANIE2405>3.0.CO ;2-3

13. Fan, S.-W.; Srivastava, A. K.; Dravid, V. P. Appl. Phys. Lett. 2009, 95, 142106. doi:10.1063/1.3243458

14. Fan, S.-W.; Srivastava, A. K.; Dravid, V. P. Sens. Actuators, B 2010, 144, 159-163. doi:10.1016/j.snb.2009.10.054

15. Prades, J. D.; Jimenez-Diaz, R.; Hernandez-Ramirez, F.; Barth, S.; Cirera, A.; Romano-Rodriguez, A.; Mathur, S.; Morante, J. R. Sens. Actuators, B 2009, 140, 337-341. doi:10.1016/j.snb.2009.04.070

16. Prades, J. D.; Jimenez-Diaz, R.; Manzanares, M.; Hernandez-Ramirez, F.; Cirera, A.; Romano-Rodriguez, A.; Mathur, S.; Morante, J. R. Phys. Chem. Chem. Phys. 2009, 11, 10881-10889. doi:10.1039/b915646a

17. Park, S.; An, S.; Mun, Y.; Lee, C. ACS Appl. Mater. Interfaces 2013, 5, 4285-4292. doi:10.1021/am400500a

18. Mun, Y.; Park, S.; An, S.; Lee, C.; Kim, H. W. Ceram. Int. 2013, 39 , 8615-8622. doi:10.1016/j.ceramint.2013.04.035

19. Lu, G.; Xu, J.; Sun, J.; Yu, Y.; Zhang, Y.; Liu, F. Sens. Actuators, B 2012, 162, 82-88. doi:10.1016/j.snb.2011.12.039

20. Gogurla, N.; Sinha, A. K.; Santra, S.; Manna, S.; Ray, S. K. Sci. Rep. 2014, 4, 6483. doi:10.1038/srep06483

21. Yang, Z.; Guo, L. J.; Zu, B. Y.; Guo, Y. N.; Xu, T.; Dou, X. C. Adv. Opt. Mater. 2014, 2, 738-745. doi:10.1002/adom.201400086

22. Zhang, D.; Liu, Z.; Li, C.; Tang, T.; Liu, X.; Han, S.; Lei, B.; Zhou, C. Nano Lett. 2004, 4, 1919-1924. doi:10.1021/nl0489283

23. Verma, V. P.; Das, S.; Hwang, S.; Choi, H.; Jeon, M.; Choi, W. Mater. Sci. Eng., B 2010, 171, 45-49. doi:10.1016/j.mseb.2010.03.066

24. Kim, I.-D.; Rothschild, A.; Lee, B. H.; Kim, D. Y.; Jo, S. M.; Tuller, H. L. Nano Lett. 2006, 6, 2009-2013. doi:10.1021/nl061197h 
25. Li, Z.; Wu, M.; Liu, T.; Wu, C.; Jiao, Z.; Zhao, B. Ultramicroscopy 2008, 108, 1334-1337. doi:10.1016/j.ultramic.2008.04.059

26. Archanjo, B. S.; Silveira, G. V.; Goncalves, A.-M. B.; Alves, D. C. B.; Ferlauto, A. S.; Lacerda, R. G.; Neves, B. R. A. Langmuir 2009, 25, 602-605. doi:10.1021/la803105f

27. Lin, C.-Y.; Chen, J.-G.; Feng, W.-Y.; Lin, C.-W.; Huang, J.-W.; Tunney, J. J.; Ho, K.-C. Sens. Actuators, B 2011, 157, 361-367. doi:10.1016/j.snb.2011.04.056

28. Ruiz, A. M.; Sakai, G.; Cornet, A.; Shimanoe, K.; Morante, J. R.; Yamazoe, N. Sens. Actuators, B 2003, 93, 509-518. doi:10.1016/S0925-4005(03)00183-7

29. Vyas, R.; Sharma, S.; Gupta, P.; Vijay, Y. K.; Prasad, A. K.; Tyagi, A. K.; Sachdev, K.; Sharma, S. K. J. Alloys Compd. 2013, 554, 59-63. doi:10.1016/j.jallcom.2012.11.059

30. Garcia, R.; Knoll, A. W.; Riedo, E. Nat. Nanotechnol. 2014, 9, 577-587. doi:10.1038/nnano.2014.157

31. Chiesa, M.; Cardenas, P. P.; Otón, F.; Martinez, J.; Mas-Torrent, M.; Garcia, F.; Alonso, J. C.; Rovira, C.; Garcia, R. Nano Lett. 2012, 12, 1275-1281. doi:10.1021/nl2037547

32. Hong, L.-Y.; Lin, H.-N. Sens. Actuators, A 2015, 232, 94-98. doi:10.1016/j.sna.2015.05.013

33. Chen, Y.-J.; Hsu, J.-H.; Lin, H.-N. Nanotechnology 2005, 16 , 1112-1115. doi:10.1088/0957-4484/16/8/020

34. Lin, H.-Y.; Chen, H.-A.; Lin, H.-N. Anal. Chem. 2008, 80, 1937-1941. doi:10.1021/ac701911j

35. Soci, C.; Zhang, A.; Xiang, B.; Dayeh, S. A.; Aplin, D. P. R.; Park, J.; Bao, X. Y.; Lo, Y. H.; Wang, D. Nano Lett. 2007, 7, 1003-1009. doi:10.1021/n1070111x

36. Prades, J. D.; Jimenez-Diaz, R.; Hernandez-Ramirez, F.; Barth, S.; Cirera, A.; Romano-Rodriguez, A.; Mathur, S.; Morante, J. R. Appl. Phys. Lett. 2008, 93, 123110. doi:10.1063/1.2988265

37. Prades, J. D.; Jimenez-Diaz, R.; Hernandez-Ramirez, F.; Cirera, A.; Romano-Rodriguez, A.; Morante, J. R. Sens. Actuators, B 2010, 144, 1-5. doi:10.1016/j.snb.2009.09.040

38. Afzal, A.; Cioffi, N.; Sabbatini, L.; Torsi, L. Sens. Actuators, B 2012, 171-172, 25-42. doi:10.1016/j.snb.2012.05.026

\section{License and Terms}

This is an Open Access article under the terms of the Creative Commons Attribution License (http://creativecommons.org/licenses/by/2.0), which permits unrestricted use, distribution, and reproduction in any medium, provided the original work is properly cited.

The license is subject to the Beilstein Journal of Nanotechnology terms and conditions: (http://www.beilstein-journals.org/bjnano)

The definitive version of this article is the electronic one which can be found at: $\underline{\text { doi:10.3762/bjnano.7.97 }}$ 